\title{
Editorial
}

\section{LA CIENCIA Y LA BELLEZA DE LA NATURALEZA}

\author{
P. Juan Roger Rodríguez Ruiz \\ / DIRECTOR
}

La universidad, como espacio del saber y la búsqueda de las primeras causas de la existencia, tiene como misión investigar, como una realidad que entraña su ser y misión y exige sumergirnos en el mundo del conocimiento que trasciende la esfera de lo puramente experimentable muestra la bondad, la belleza y la verdad.

No debe extrañar que la belleza de la naturaleza ha motivado al espíritu humano de los investigadores, quienes confiaron en que la naturaleza es bella y armoniosa y sintieron con fuerza que la belleza de la naturaleza sería más evidente para su entendimiento que las leyes propuestas por las teorías.

Así, la investigación científica requiere del aporte de las disciplinas que ayudan a comprender el alma humana y ésto "resulta de la necesidad del diálogo entre la razón y la fe". Un diálogo necesario para que los frutos de las investigaciones científicas, en las diversas disciplinas, sirvan al desarrollo pleno del ser humano. Esta realidad indica que no se puede separar la razón del alma, tampoco se puede transmitir totalmente la ciencia sin tener en cuenta las necesidades del alma humana, que está abierta al infinito.

En este sentido, el desarrollo de las ciencias conlleva tantas cuestiones éticas que deberían ser resueltas respetando la autonomía de las ciencias y el espíritu de la verdad. Sin embargo se verifica que "la tendencia colegial al conocimiento de la verdad sobre el ser humano, la dignidad de la persona, el valor de la vida y, al mismo tiempo, la grandiosidad de los resultados científicos en todas las disciplinas será muy útil para profundizar en el saber transmitido”.

Estas consideraciones motivan a seguir profundizando en el espíritu humano, en la grandeza de la creación y su admiración por la belleza. En este contexto, queremos destacar la obra de nuestro editor Saniel Lozano, escritor, periodista, ensayista, crítico y profesor universitario, quien acaba de ser incorporado como miembro del Instituto de Estudios Vallejianos como distinguido escritor en los géneros de narración, poesía, ensayo, crítica y periodismo cultural. 
El Doctor Saniel Lozano ha logrado perfilar una presencia creativa e innovadora que busca permanentemente la belleza de lo creado, recreando con sabiduría el tesoro escondido que logra descubrir en su contemplación.

En este contexto, la ciencia revestida de la fe es transformada, de alguna manera redimida; el intelecto humano se agudiza y es capaz de ver mucho más allá y gozar de Dios ante la grandiosidad de sus obras en la humildad y la contemplación, en el silencio del corazón donde Dios habla y educa.

Benedicto XVI indicó que "es justamente el amor de Dios que hace aguda y penetrante la mirada de la búsqueda y ayuda a captar aquello que ninguna investigación está en capacidad de percibir". De allí, la necesidad de leer en los otros la imagen de Dios amor y en la creación su impronta. Sin amor, también la ciencia pierde su nobleza. Sólo el amor garantiza la humanidad de la investigación”.

Por otro lado, dado los diversos desafios ante la ciencia y el entendimiento sobre la realidad del ser humano, en medio de los avances tecnológicos que se dan cada vez más rápido, se verifica que los múltiples descubrimientos, las tecnologías innovadoras que se suceden con un ritmo tan rápido, son, con razón, motivo de orgullo, pero, a menudo, no son sin consecuencias preocupantes". Benedicto XVI alertó que una "crisis de pensamiento", en la que el hombre se ve "rico en recursos, pero no igualmente rico en sus objetivos, el hombre de nuestro tiempo vive a menudo condicionado por el relativismo y por el reduccionismo, que llevan a perder el sentido de las cosas, casi ofuscado por la eficacia técnica, olvida el horizonte esencial de la necesidad de sentido, relegando la dimensión trascendente a la insignificancia”.

Así, el pensamiento se debilita y gana terreno un empobrecimiento ético, que nubla las referencias normativas de valor y disminuye la exigencia de profundizar en las ciencias seculares y en el mundo del conocimiento.

Conviene tener en cuenta que la investigación científica y la búsqueda de sentido brotan de un mismo manantial, ese Logos que preside la obra de la creación y guía la inteligencia de la historia. Una mentalidad fundamentalmente 'tecnopráctica' genera un arriesgado desequilibrio entre lo que es técnicamente posible y lo que es moralmente bueno, con consecuencias imprevisibles. De allí la necesidad de descubrir el vigor del significado y el dinamismo de la trascendencia.

En este sentido, para que la investigación humana llegue a buen puerto es necesario "redescubrir el lugar donde surge, que la investigación científica 
comparte con la búsqueda de la fe, casi una exigencia complementaria de la inteligencia de lo real". Sin embargo, la cultura positivista, excluyendo del debate científico la pregunta sobre Dios, determina el declive del pensamiento y el debilitamiento de la capacidad de la inteligencia de lo real”.

Se puede afirmar que la búsqueda de la verdad, vivida en su integridad, es iluminada por ciencia y fe, y de estas dos 'alas' toma impulso y fuerza, sin perder jamás la justa humildad, el sentido del propio límite. Y en esta búsqueda, la tarea de la Universidad Católica es insustituible, "lugar en el que la relación educativa está colocada al servicio de la persona en la construcción de una cualificada competencia científica, radicada en un patrimonio de saberes que el paso de las generaciones ha destilado en sabiduría de vida; lugar en el que la relación de cura no es un oficio, sino una misión; donde la caridad es la primera cátedra y el rostro del hombre que sufre el Rostro mismo de Cristo: 'lo habéis hecho a mi'".

"La Universidad Católica, en el trabajo cotidiano de experimentación, de enseñanza y de estudio, vive en esta traditio, que expresa la propia potencialidad de innovación: ningún progreso, mucho menos sobre el plano cultural, se nutre de mera repetición, si no que exige un inicio siempre nuevo".

Se requiere, además, aquella disponibilidad al debate y al diálogo que abre la inteligencia y testimonia la rica fecundidad del patrimonio de la fe. Así, se da forma a una sólida estructura de personalidad, donde la identidad cristiana penetra el vivir cotidiano y se expresa desde el interno de una profesionalidad excelente.

En definitiva, la Universidad Católica está llamada, hoy, a ser institución ejemplar que no limita el aprendizaje a la funcionalidad de un resultado económico, sino que amplía el respiro sobre proyectos en los que el don de la inteligencia investiga y desarrolla los dones del mundo creado, superando una visión sólo productiva y utilitarista de la existencia, porque "el ser humano está hecho para el don, que expresa y actúa la dimensión de trascendencia". 